\title{
Highly enantio- and diastereoselective reductive aldol reactions catalyzed by chiral spiro bisphosphine oxides
}

\author{
Panke Zhang, Jiawang Liu, Zheng Wang, Kuiling Ding* \\ State Key Laboratory of Organometallic Chemistry, Shanghai Institute of Organic Chemistry, Chinese Academy of Sciences, Shanghai 200032, China
}

\section{A R T I C L E I N F O}

Article history:

Received 4 September 2014

Accepted 26 September 2014

Published 20 January 2015

\section{Keywords:}

Asymmetric catalysis

Enone

Lewis base

Reductive aldol reaction

Spiro bisphosphine oxide
Aldehyde

\section{A B S T R A C T}

A spiro bisphosphine oxide (SpinPO) was found to be an efficient chiral Lewis base catalyst in asymmetric reductive aldol reaction of enones and aldehydes in the presence of trichlorosilane as the reductant, affording a variety of $\beta$-hydroxyketones in good yields with moderate to high levels of diastereo- and enantioselectivities.

(C) 2015, Dalian Institute of Chemical Physics, Chinese Academy of Sciences. Published by Elsevier B.V. All rights reserved.

\section{Introduction}

The reductive aldol reaction between an $\alpha, \beta$-unsaturated carbonyl compound and an aldehyde or ketone is a powerful method for stereocontrolled $\mathrm{C}-\mathrm{C}$ bond formation [1]. These tandem reactions generally proceed via conjugate reduction of an enone or enoate followed by aldol reaction of the in-situ generated enolate with an aldehyde or ketone electrophile. By this way, the $\beta$-hydroxy carbonyl products with several contiguous stereocenters can be directly constructed in a one-pot fashion, thus providing an attractive alternative approach for stereocontrolled synthesis of aldols. Following the seminal studies by Revis and Hilty in 1987 [2], a variety of catalysts based on $\mathrm{Rh}$ [3], Co [4], Cu [5,6], Ni [7], In [8,9], Sn [10], etc. [11], have been developed for inter- or intramolecular reductive aldol reactions, wherein mostly silanes or molecular hy- drogen [12], sometimes diethylzinc [13], or trialkylborane [7] were used as the stoichiometric reductants. The first example of the asymmetric reductive aldol reaction was reported by Morken et al. in 2000 [14], and since then a number of chiral metal-ligand complexes based on Ir [15], Rh [16-21], or $\mathrm{Cu}$ [22-29] have also been used as the catalysts to control the stereochemistry of the reactions, delivering various chiral aldol products with synthetically useful diastereo- and enantioselectivities. A notable progress in this area was made recently by Nakajima and coworkers [30-33], who have developed highly enantio- and diastereoselective asymmetric reductive aldol reactions using chiral bisphosphine oxides as Lewis base catalysts. It is also noteworthy that over the decades, Lewis base catalysis has been established as an attractive and highly competitive alternative to the methods employing metal complexes, providing elegant solutions to numerous challenging organic

\footnotetext{
*Corresponding author. Tel: +86-21-54925146; Fax: +86-21-64166128; E-mail: kding@mail.sioc.ac.cn This work was supported by the National Basic Research Program of China (2010CB833300), the National Natural Science Foundation of China (21121062, 21232009), the Chinese Academy of Sciences, and the Science and Technology Commission of Shanghai Municipality. The supporting information of this article is available from the corresponding author. DOI: 10.1016/S1872-2067(14)60241-2 | http://www.sciencedirect.com/science/journal/18722067 | Chin. J. Catal., Vol. 36, No. 1, January 2015
} 
transformations in general [34], and including the Mukaiyama aldol reactions in particular [35]. In this context, we recently reported the successful development of a class of spiro[4,4]1,6-nonadiene-based phosphino-oxazoline ligands/catalysts [36-47] and bisphosphine oxides (SpinP0) [48], and the use of SpinPO as chiral Lewis base catalysts in the direct asymmetric double-aldol reaction of ketones with aldehydes. As an ongoing effort to develop efficient Lewis base catalyzed asymmetric synthesis, herein we report a highly enantio- and diastereoselective reductive aldol reaction of enones and aldehydes with SpinPO as the catalyst and trichlorosilane as the reductant.

\section{Experimental}

\subsection{General methods}

Unless otherwise noted, all reactions and manipulations involving air- or moisture-sensitive compounds were performed using standard Schlenk techniques or in a glovebox. All solvents were purified and dried using standard procedures. Melting points were measured on an RY-I apparatus and uncorrected. ${ }^{1} \mathrm{H},{ }^{13} \mathrm{C},{ }^{31} \mathrm{P}$, and ${ }^{19} \mathrm{~F}$ NMR spectra were recorded on Varian Mercury $300 \mathrm{MHz}$ or $400 \mathrm{MHz}$ spectrometers. Chemical shifts ( $\delta$ values) were reported in ppm downfield from internal TMS $\left({ }^{1} \mathrm{H} \mathrm{NMR}\right)$, internal $\mathrm{CDCl}_{3}\left({ }^{13} \mathrm{C}\right.$ $\mathrm{NMR}$ ), external 85\% $\mathrm{H}_{3} \mathrm{PO}_{4}$ (31P NMR), and external $\mathrm{CF}_{3} \mathrm{CO}_{2} \mathrm{H}$ $\left({ }^{19} \mathrm{~F}\right.$ NMR), respectively. Optical rotations were determined using a Perkin Elmer $341 \mathrm{MC}$ polarimeter. The IR spectra were measured on a Bruker Tensor 27 FT-IR spectrometer. ESI-MS and HRMS (ESI) spectra were taken on a Shimadzu LCMS2010EV and an Agilent Technologies 6224 TOF LC/MS spectrometer, respectively. HPLC analyses were performed on a JASCO 2089 liquid chromatograph. Trichlorosilane, the $\alpha, \beta$ unsaturated ketones, and aldehydes were purchased from commercial sources and used without further purification.

\subsection{Synthesis of the chiral spiro[4,4]-1,6-nonadiene-based bisphosphine oxides (SpinPO)}

The chiral SpinPO $(S)$-1a-c, $(R)-\mathbf{1 d - e},(-)-\mathbf{1 f}$, and $(S)-\mathbf{1 g}$ (Fig. 1) were synthesized by following our previously reported procedures [48].

\subsection{General procedure for the spiro phosphine oxides catalyzed asymmetric reductive aldol reactions}

To a Schlenk tube containing a stirred solution of the enone
2 (0.25 mmol), chiral phosphine oxide $(S)-1 c(15.1 \mathrm{mg}, 0.025$ mmol $)$, and the aldehyde $3(0.30 \mathrm{mmol})$ in anhydrous THF (1.0 $\mathrm{mL})$ was added dropwise trichlorosilane $(0.17 \mathrm{~mL}, 0.5 \mathrm{mmol})$ at $-78{ }^{\circ} \mathrm{C}$. The resultant yellowish emulsion was stirred at -78 ${ }^{\circ} \mathrm{C}$ for $24 \mathrm{~h}$, and the reaction was quenched by saturated aqueous sodium bicarbonate solution $(5.0 \mathrm{~mL})$. The mixture was stirred for $0.5 \mathrm{~h}$ at this temperature, warmed to r.t., and stirred for further $0.5 \mathrm{~h}$, and the solids were removed by filtration through a pad of celite. The filtrate was extracted with ethyl acetate $(20 \mathrm{~mL} \times 3)$, and the combined organic phases were washed sequentially with saturated aqueous sodium bicarbonate solution and brine, dried over anhydrous sodium sulfate, and filtered. After removal of the volatiles under reduced pressure, the residue was purified by column chromatography on silica gel with petroleum ether/EtOAc (15/1-10/1) as the eluents, to give the aldol product 4 as a diastereomeric mixture. The diastereomeric ratio (dr, syn/anti) and the enantiomeric excess (ee) values of the optically enriched $4 \mathbf{4 a}-\mathbf{q}$ were determined by chiral HPLC, while the ${ }^{1} \mathrm{H}$, ${ }^{13} \mathrm{C}$, and ${ }^{19} \mathrm{~F}$ NMR spectral data were recorded on the diastereomeric samples of $\mathbf{4 a - q}$ obtained from the corresponding reductive aldol reactions catalyzed by racemic BINAP dioxide (BINAPO) or achiral triphenylphosphine oxide.

\section{Results and discussion}

\subsection{SpinPO catalyzed asymmetric reductive aldol reaction of chalcone with benzaldehyde}

\subsubsection{Optimization of the reaction conditions}

Nakajima et al. [30] have shown that trichlorosilane can be activated by an appropriate Lewis base to undergo conjugate reduction with an enone, and the in situ generated trichlorosilyl enolate may react with a coexisting aldehyde to give the reductive aldol product. Denmark et al. [49-52] have extensively investigated the aldol additions of trichlorosilyl enolates derived from various carbonyl compounds and demonstrated that the reactions proceeded via the catalysis of some hypervalent silicon species stabilized by a suitable Lewis base. Inspired by these pioneering studies, we initiated the study by examining the viability of SpinPo catalysts of asymmetric reductive aldol reaction, using substoichiometric (S)-1a in the reaction of chalcone (2a) and benzaldehyde (3a) with two equivalents of trichlorosilane as the reductant. As shown in Table 1, a large variation in reactivity and stereoselectivity was observed, depending on the temperature, solvent, and/or catalyst loading used in the reactions. For the

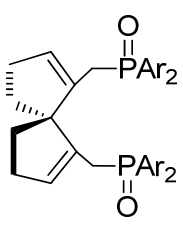

(S)-1a: $\mathrm{Ar}=\mathrm{C}_{6} \mathrm{H}_{5}$

(S)-1b: $\mathrm{Ar}=4-\mathrm{MeOC}_{6} \mathrm{H}_{4}$

(S)-1c: $\mathrm{Ar}=4-\mathrm{MeC}_{6} \mathrm{H}_{4}$

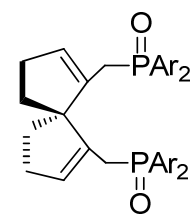

(R)-1d: $\mathrm{Ar}=3,5-\mathrm{Me}_{2} \mathrm{C}_{6} \mathrm{H}_{3}$

$(R)-1 e: \mathrm{Ar}=2-\mathrm{MeC}_{6} \mathrm{H}_{4}$

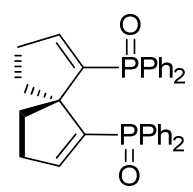

(S)-1g

Fig. 1. Chiral spiro[4,4]-1,6-nonadiene-based bisphosphine oxides $(S)-\mathbf{1 a - c},(R)-\mathbf{1 d}-\mathbf{e},(-)-\mathbf{1 f}$, and $(S)-\mathbf{1 g}$. 
Table 1

(S)-1a catalyzed asymmetric reductive aldol reaction of chalcone (2a) with benzaldehyde (3a).

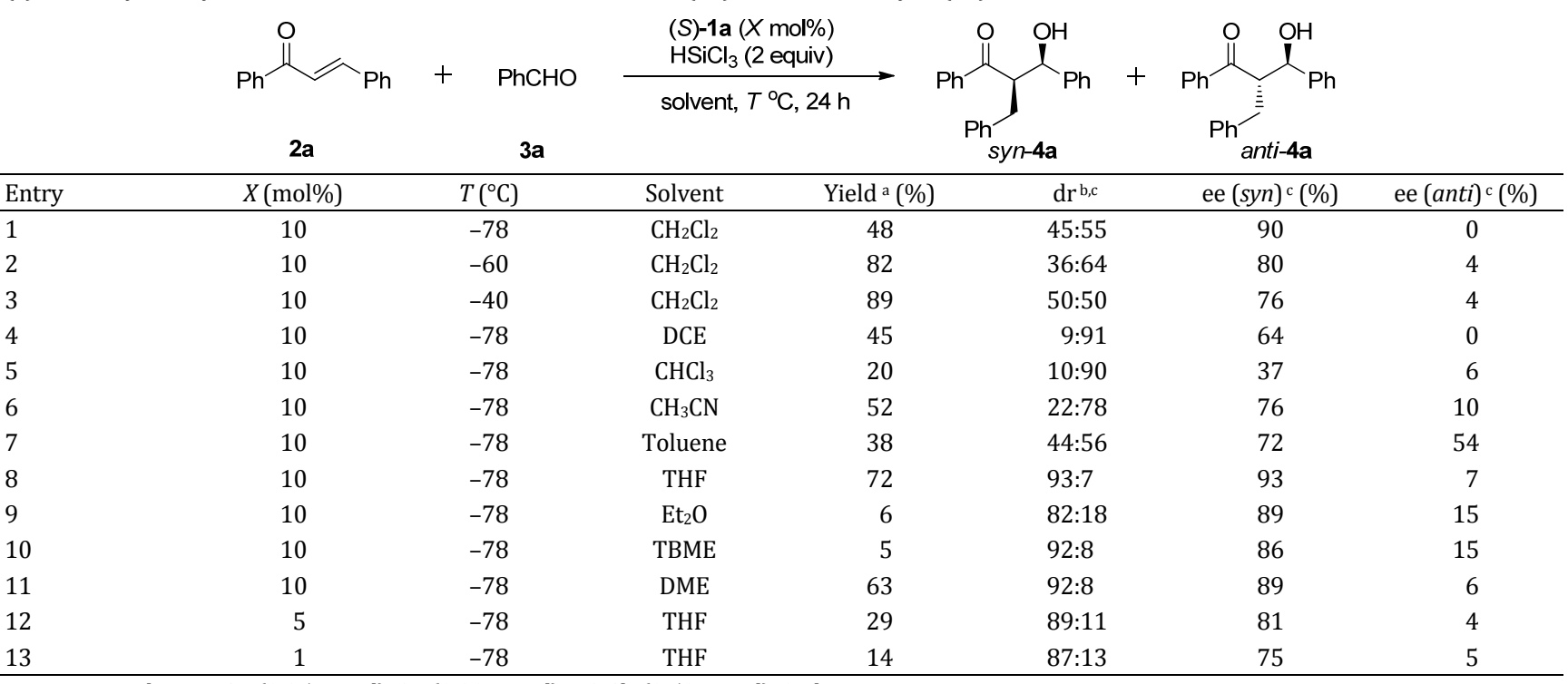

Reaction conditions: 2a $(0.25 \mathrm{mmol}), \mathbf{3 a}(0.30 \mathrm{mmol}), \mathrm{HSiCl}_{3}(0.50 \mathrm{mmol}), 24 \mathrm{~h}$

a Yield of the isolated product 4a. ${ }^{\mathrm{b}} \mathrm{dr}=$ syn:anti. ${ }^{\mathrm{c}}$ Determined by chiral HPLC analyses.

reactions performed in dichloromethane in the presence of 10 mol\% of $(S)-1 \mathrm{a}$, varying the temperatures from -78 to $-40{ }^{\circ} \mathrm{C}$ raised the yield of the aldol adduct $\mathbf{4 a}$, but the diastereoselectivities (dr) were only modest (entries 1-3). Replacing dichloromethane with other types of aprotic polar or nonpolar solvents (entries 4-11) has been found to improve the dr values in most cases, but sometimes at a cost of poor conversion (entries 5, 9, and 10) or moderate ee values (entries 4 and 6). The coordinating ether THF and DME turned out to be the most favorable solvents for the reaction, affording preferentially syn-4a in good yields and high levels of diastereo- and enantioselectivities (entries 8 and 11). Further attempts to optimize the reaction by reducing the catalyst loadings of $(S)$-1a from 10 to 5 or $1 \mathrm{~mol} \%$ were unsuccessful, resulting in poor yields and decreased $\mathrm{dr}$ and ee values (entries 12 and 13 vs 8 ). Thus, the optimized conditions as in entry 8 were used in subsequent catalyst survey studies.

\subsubsection{Catalyst optimization}

To further optimize the reaction results, the family of SpinPo catalysts 1a-g was screened against reductive aldol reaction of chalcone (2a) and benzaldehyde (3a) using trichlorosilane as the reductant. The reactions were allowed to proceed in THF for $24 \mathrm{~h}$ at $-78^{\circ} \mathrm{C}$ in the presence of $10 \mathrm{~mol} \%$ of 1a-g, and the relevant results are summarized in Table 2. Generally moderate to high yields (41\%-86\%) were obtained for the $\beta$-hydroxyketone $\mathbf{4 a}$, whereas the sense and level of stereoselection fluctuated to some degree depending upon the SpinPo structure (entries 1-7). Both the steric effects and the skeleton flexibility in SpinPO structure appeared to be important for the diastereo- and enantioselectivity. While high diastereoselectivities (syn/anti ca 96/4) and excellent

Table 2

Screening of the SpinPO 1a-g for the catalytic asymmetric reductive aldol reaction.

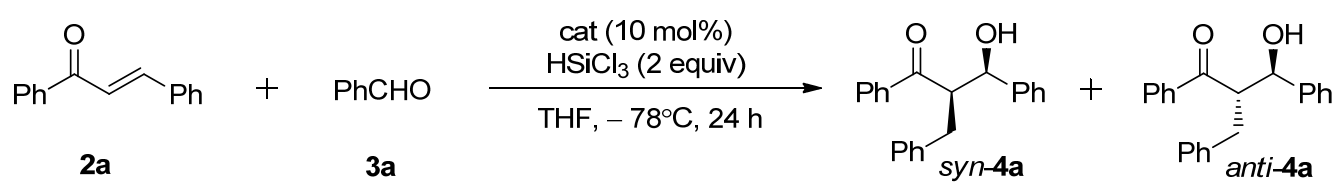

\begin{tabular}{lccccc}
\hline Entry & Catalyst & Yield $^{\mathrm{a}}(\%)$ & $\mathrm{dr}$ b,c & ee $(\text { syn })^{\mathrm{c}}(\%)$ & ee $(\text { anti })^{\mathrm{c}}(\%)$ \\
\hline 1 & $(S)-\mathbf{1 a}$ & 72 & $93: 7$ & $93(R, R)$ & 7 \\
2 & $(S)-\mathbf{1 b}$ & 78 & $96: 4$ & $92(R, R)$ & 14 \\
3 & $(S)-\mathbf{1 c}$ & 86 & $96: 4$ & $94(R, R)$ & 13 \\
4 & $(R)-\mathbf{1 d}$ & 59 & $82: 18$ & $81(S, S)$ & 4 \\
5 & $(R)-\mathbf{- 1}$ & 41 & $20: 80$ & $0(S, S)$ & 14 \\
6 & $(-)-\mathbf{1 f}$ & 82 & $97: 3$ & $68(S, S)$ & 6 \\
7 & $(S)-\mathbf{1 g}$ & 78 & $94: 6$ & $15(R, R)$ & 1 \\
\hline
\end{tabular}

Reaction conditions: $\mathbf{2 a}(0.25 \mathrm{mmol}), \mathbf{3 a}(0.30 \mathrm{mmol}), \mathrm{HSiCl}_{3}(0.50 \mathrm{mmol}), \mathbf{1}(0.025 \mathrm{mmol}), \mathrm{THF}(1.0 \mathrm{~mL}),-78^{\circ} \mathrm{C}, 24 \mathrm{~h}$.

${ }^{a}$ Yield of the isolated product 4a. ${ }^{\mathrm{b}} \mathrm{dr}=$ syn:anti. ${ }^{\mathrm{c}}$ Determined by chiral HPLC analyses. The absolute configurations of the syn-4a were assigned by comparison of the specific rotations with that reported in Ref. [31]. 
enantioselectivities (92\%-94\% ee) for syn-4a were reached in the cases of (S)-1a-c (entries 1-3), considerable losses in stereoselectivities were observed for the reactions catalyzed by $(R)$-1d-e with bulkier aryl substituents (entries 4 and 5). In contrast to flexible 1a-c with two methylene moieties between the spiro scaffold and the $\mathrm{Ar}_{2} \mathrm{PO}$ units, their structurally more rigid analogs 1f-g bearing only one or no flexible methylene group led to a substantial decline in enantioselectivities (entries 6 and 7 vs 1). Among the SpinPo family, (S)-1c was identified as the optimal Lewis base catalyst for the reaction, affording preferentially syn-4a in high levels of diastereo- and enantioselectivities (dr 96/4, 94\% ee, entry 3).

\subsection{Substrate scope for the asymmetric reductive aldol reaction}

The substrate adaptability of the protocol was evaluated with the reductive aldol reactions of chalcones ( $2 \mathbf{a}$ and $2 \mathbf{c}$ ) or (E)-1-phenylbut-2-en-1-one (2b) and various aromatic, aliphatic, $\alpha, \beta$-unsaturated, and heteroaromatic aldehydes (3a-p) using trichlorosilane as the hydride source. The reactions were performed in THF at $-78{ }^{\circ} \mathrm{C}$ for $24 \mathrm{~h}$ using 10 mol\% of $(S)-1 c$ as the catalyst, and the representative results were presented in Table 3. The $\beta$-hydroxyketone products $4 \mathbf{a}-\mathbf{r}$ were obtained in $45 \%-88 \%$ yields, generally good to excellent diastereo- and enantioselectivities (dr 8/92-100/0, up to $95 \%$ ee for the syn-isomers). For the reactions of chalcone (2a) with the aromatic aldehydes $\mathbf{3 a}-\mathbf{j}$, steric properties of the aldehyde component seem to be less significant, as aldehydes $\mathbf{3 a - f}$ and $\mathbf{3 j}$ afforded the corresponding aldol products $\mathbf{4 a}-\mathbf{f}$ and $\mathbf{4 j}$ with comparable stereoselectivities (dr 90/10-97/3, 78\%-94\% ee for the major syn-diastereomers), regardless of the $o^{-}, m^{-}$, or $p$-locations of the electron-donating substituent on their phenyl rings (entries 1-6 and 10). On the other hand, the electronic nature of the aldehydes appears to play a major role in determining the stereoselectivities. Compared to their electronrich homologues, aldehydes $\mathbf{3 g}$ and $\mathbf{3 i}$ bearing strongly electron-withdrawing $p$-nitro or $p$-trifluomethyl groups, respectively, gave the products $\mathbf{4 g}$ and $\mathbf{4 i}$ in drastically reduced stereoselectivities (syn/anti 46/54 and 53/47, 15\%, and 44\% ee for the syn- and racemic for anti-isomers, respectively) (entries 7 and 9), probably as a result of less favorable interaction with the hypervalent silicon species. The reaction of $\mathbf{2 a}$ and $\mathbf{3 h}$ is an exception, therein a high level of diastereo- and enantioselectivity was attained (dr 95/5, 94\% ee for syn-4h) despite the presence of electron-withdrawing $\mathrm{F}$ atom on the aldehyde reactant (entry 8). Aldehydes $\mathbf{3 k}-\mathbf{m}$ containing heteroaromatic or naphthyl groups also reacted smoothly with 2a (entries 11-13), to deliver $\beta$-hydroxyketone products $4 \mathbf{k}-\mathbf{m}$

Table 3

(S)-1c catalyzed asymmetric reductive aldol reaction of enones (2a-b) with aldehydes (3a-o).

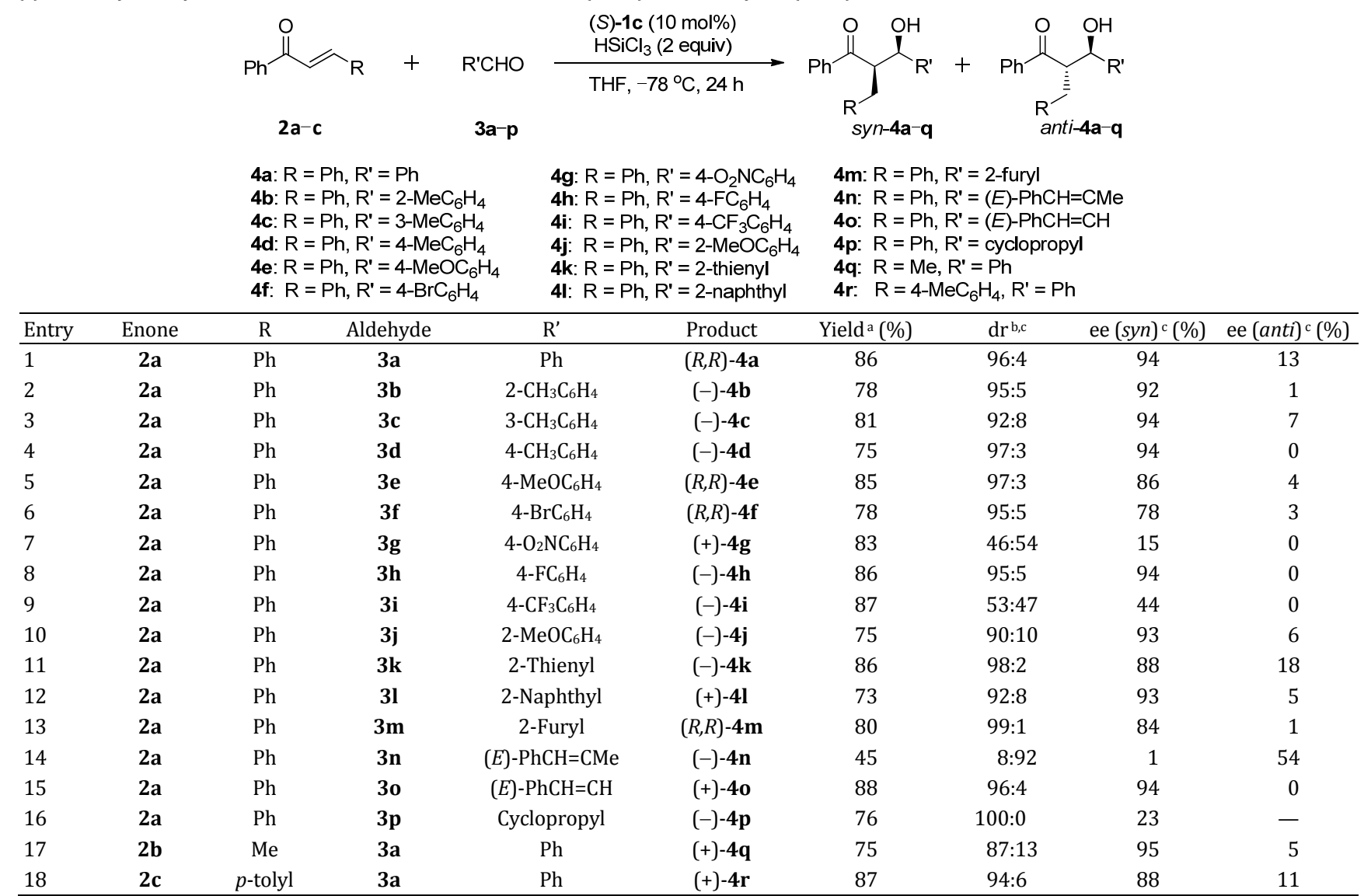

Reaction conditions: $2(0.25 \mathrm{mmol}), 3(0.30 \mathrm{mmol}), \mathrm{HSiCl}_{3}(0.50 \mathrm{mmol}),(S)-\mathbf{1 c}(0.025 \mathrm{mmol}), \mathrm{THF}(1.0 \mathrm{~mL}),-78^{\circ} \mathrm{C}, 24 \mathrm{~h}$.

a Yield of the isolated products $\mathbf{4 a - r} \cdot{ }^{\mathrm{b}} \mathrm{dr}=$ syn:anti. ${ }^{\mathrm{c}}$ Determined by chiral HPLC analyses. Where appropriate, the absolute configurations were assigned by comparison of the specific rotations with those reported in Ref. [31]. 
in good yields (73\%-86\%) with a strong preference for the syndiastereomers (dr 92/8-99/1) and high enantioselectivities (84\%-93\% ee). High levels of diastereoselectivity were also observed in the reactions involving $\alpha, \beta$-unsaturated aldehydes 3n and 30 (entries 14 and 15), but only the reaction of cinnamaldehyde $\mathbf{3 o}$ gave the corresponding adduct syn-4o with excellent enantioselectivity as well ( $94 \%$ ee, entry 15). The reaction of $\mathbf{2 a}$ with alkyl aldehyde was examined using $\mathbf{3 p}$ as a substrate, to result in the exclusive formation of syn-4o albeit with a modest ee value (entry 16). Enone $\mathbf{2 b}$ with an aliphatic vinyl substituent (Me) was also used as the nucleophilic partner in the reductive aldol reaction with $\mathbf{3 a}$, giving the high levels of stereoselectivity ( $\mathrm{dr} 87 / 13,95 \%$ ee) for the syn-aldol product 4q (entry 17). Finally, the chalcone derivative 2c also underwent a smooth reductive aldol reaction with $\mathbf{3 a}$ under the standard conditions, affording the corresponding aldol product 4r in good yield (87\%) with high diastereo- and enantioselectivities (syn/anti $=94: 6,88 \%$ ee for syn, entry 18).

\section{Conclusions}

We have developed a highly diastereo- and enantioselective synthesis of optically enriched $\beta$-hydroxyketones. Using the spiro bisphosphine oxides SpinPO as chiral Lewis base catalysts, the asymmetric reductive aldol reactions of enones and a range of aldehydes proceeded smoothly with trichlorosilane reductant, to afford the corresponding aldol adducts $4 \mathbf{4 a}-\mathbf{r}$ in $45 \%-88 \%$ yields, generally high syn-diastereoselectivity, and good to excellent enantioselectivity (up to 95\% ee). Substrates with diverse stereoelectronic natures were tolerated, generally affording good yields and high stereoselectivities.

\section{References}

[1] Nishiyama H, Shiomi T. Top Curr Chem, 2007, 279: 105

[2] Revis A, Hilty T K. Tetrahedron Lett, 1987, 28: 4809

[3] Matsuda I, Takahashi K, Sato S. Tetrahedron Lett, 1990, 31: 5331

[4] Isayama S, Mukaiyama T. Chem Lett, 1989: 2005
[5] Chiu P, Leung S K. Chem Commun, 2004: 2308

[6] Welle A, Diez-Gonzalez S, Tinant B, Nolan S P, Riant O. Org Lett, 2006, 8: 6059

[7] Chrovian C C, Montgomery J. Org Lett, 2007, 9: 537

[8] Miura K, Yamada Y, Tomita M, Hosomi A. Synlett, 2004: 1985

[9] Shibata I, Kato H, Ishida T, Yasuda M, Baba A. Angew Chem Int Ed, 2004, 43: 711

[10] Shibata I, Tsunoi S, Sakabe K, Miyamoto S, Kato H, Nakajima H, Yasuda M, Baba A. Chem Eur J, 2010, 16: 13335

[11] Taylor S J, Morken J P. J Am Chem Soc, 1999, 121: 12202

[12] Jang H Y, Krische M J. Acc Chem Res, 2004, 37: 653

[13] Lam H W, Joensuu P M, Murray G J, Fordyce E A F, Prieto O, Luebbers T. Org Lett, 2006, 8: 3729

[14] Taylor S J, Duffey M O, Morken J P. J Am Chem Soc, 2000, 122: 4528

[15] Zhao C X, Duffey M O, Taylor S J, Morken J P. Org Lett, 2001, 3: 1829

[16] Russell A E, Fuller N O, Taylor S J, Aurriset P, Morken J P. Org Lett, 2004, 6: 2309

[17] Fuller N O, Morken J P. Synlett, 2005, 1459

[18] Nishiyama H, Shiomi T, Tsuchiya Y, Matsuda I. J Am Chem Soc, 2005, 127: 6972

[19] Shiomi T, Nishiyama H. Org Lett, 2007, 9: 1651

[20] Shiomi T, Adachi T, Ito J, Nishiyama H. Org Lett, 2009, 11: 1011

[21] Yang Y F, Shi T, Zhang X H, Tang Z X, Wen Z Y, Quan J M, Wu Y D. Org Biomol Chem, 2011, 9: 5845

[22] Lam H W, Joensuu P M. Org Lett, 2005, 7: 4225

[23] Chuzel 0, Deschamp J, Chausteur C, Riant O. Org Lett, 2006, 8: 5943

[24] Deschamp J, Chuzel 0, Hannedouche J, Riant O. Angew Chem Int Ed, 2006, 45: 1292

[25] Zhao D B, Oisaki K, Kanai M, Shibasaki M. J Am Chem Soc, 2006, 128: 14440

[26] Lipshutz B H, Amorelli B, Unger J B. J Am Chem Soc, 2008, 130: 14378

[27] Kato M, Oki H, Ogata K, Fukuzawa S. Synlett, 2009: 1299

[28] Deschamp J, Hermant T, Riant 0. Tetrahedron, 2012, 68: 3457

[29] Ou J, Wong W T, Chiu P. Org Biomol Chem, 2012, 10: 5971

[30] Sugiura M, Sato N, Kotani S, Nakajima M. Chem Commun, 2008: 4309

[31] Sugiura M, Sato N, Sonoda Y, Kotani S, Nakajima M. Chem Asian J, 2010, 5: 478

\section{Graphical Abstract}

Chin. J. Catal., 2015, 36: 100-105 doi: 10.1016/S1872-2067(14)60241-2

\section{Highly enantio- and diastereoselective reductive aldol reactions catalyzed by chiral spiro bisphosphine oxides}

Panke Zhang, Jiawang Liu, Zheng Wang, Kuiling Ding*

Shanghai Institute of Organic Chemistry, Chinese Academy of Sciences

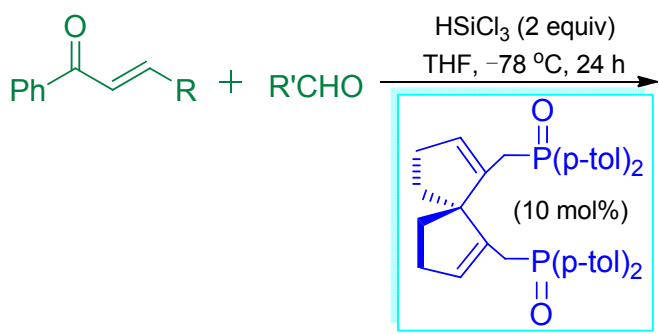

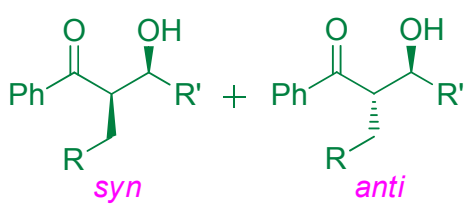

18 examples, $45 \%-88 \%$ yields syn/anti 8:92-100:0, up to $95 \%$ ee

A spiro bisphosphine oxide (SpinP0) was found to be a highly enantio- and diastereoselective Lewis base catalyst in reductive aldol reactions of enones and aldehydes in the presence of trichlorosilane as the stoichiometric reductant. 
[32] Ohmaru Y, Sato N, Mizutani M, Kotani S, Sugiura M, Nakajima M. Org Biomol Chem, 2012, 10: 4562

[33] Osakama K, Sugiura M, Nakajima M, Kotani S. Tetrahedron Lett, 2012, 53: 4199

[34] Denmark S E, Beutner G L. Angew Chem Int Ed, 2008, 47: 1560

[35] Beutner G L, Denmark S E. Angew Chem Int Ed, 2013, 52: 9086

[36] Han Z B, Wang Z, Zhang X M, Ding K L. Sci Sin Chin (韩召斌, 王正, 张绪穆, 丁奎岭. 中国科学: 化学), 2010, 40: 950

[37] Ding K L, Han Z B, Wang Z. Chem Asian J, 2009, 4: 32

[38] Han Z B, Wang Z, Zhang X M, Ding K L. Angew Chem Int Ed, 2009, 48: 5345

[39] Han Z B, Wang Z, Zhang X M, Ding K L. Tetrahedron: Asymmetry, 2010, 21: 1529

[40] Han Z B, Wang Z, Zhang X M, Ding K L. Chin Sci Bull, 2010, 55: 2840

[41] Zhang Y, Han Z B, Li F Y, Ding K L, Zhang A. Chem Commun, 2010, 46: 156

[42] Han Z B, Wang Z, Ding K L. Adv Synth Catal, 2011, 353: 1584

[43] Shang J, Han Z B, Li Y, Wang Z, Ding K L. Chem Commun, 2012, 48:
5172

[44] Liu X, Han Z B, Wang Z, Ding K L. Acta Chim Sin (刘旭, 韩召斌, 王 正, 丁奎岭. 化学学报), 2014, 72: 849

[45] Liu X, Han Z B, Wang, Z, Ding K L. Sci China Chem, 2014, 57: 1073

[46] Liu X, Han Z B, Wang Z, Ding K L. Angew Chem Int Ed, 2014, 53: 1978

[47] Xie J H, Zhou Q L. Acta Chim Sin (谢建华, 周其林. 化学学报), 2014, 72: 778

[48] Zhang P K, Han Z B, Wang Z, Ding K L. Angew Chem Int Ed, 2013, 52: 11054

[49] Denmark S E, Winter S B D, Su X P, Wong K T. J Am Chem Soc, 1996, 118: 7404

[50] Denmark S E, Stavenger R A, Winter S B D, Wong K T, Barsanti P A. JOrg Chem, 1998, 63: 9517

[51] Denmark S E, Pham S M, Stavenger R A, Su X P, Wong K T, Nishigaichi Y.J Org Chem, 2006, 71: 3904

[52] Denmark S E, Eklov B M, Yao P J, Eastgate M D. J Am Chem Soc, 2009, 131: 11770

\title{
手性螺环双膦氧化物催化的不对称还原-Aldol反应
}

\author{
张攀科, 刘家旺, 王正, 丁奎岭* \\ 中国科学院上海有机化学研究所金属有机国家重点实验室, 上海200032
}

摘要: 以螺环膦氧化合物为催化剂及三氯硅氢为还原剂, 发展了手性Lewis碱催化的烯酮与醛的不对称还原-Aldol反应. 该类催 化剂在查耳酮以及类似物与各种醛的不对称还原-Aldol反应中表现出较高的反应活性和良好的立体选择性, 以较好的产率 (45\%-88\%)、中等到优秀的非对映选择性(8:92-100:0)以及最高达95\%的ee值得到相应的还原Aldol产物.

关键词：醛; 不对称催化; 烯酮; 路易斯碱; 还原Aldol反应; 螺环膦氧化合物

收稿日期: 2014-09-04. 接受日期: 2014-09-26. 出版日期: 2015-01-20.

*通讯联系人. 电话: (021)54925146; 传真: (021)64166128; 电子信箱: kding@mail.sioc.ac.cn

基金来源：国家重点基础研究发展计划(973计划, 2010CB833300); 国家自然科学基金(21121062, 21232009); 中国科学院; 上海 市科学技术委员会.

本文的英文电子版由Elsevier出版社在ScienceDirect上出版(http://www.sciencedirect.com/science/journal/18722067). 